\title{
Conceptual Profile of Vibrio Species and the Associated Physicochemical Dynamics of Some Aquatic Reservoirs in Andoni Local Government Area of Rivers State, Nigeria
}

\author{
T. Sampson (Corresponding Author) \\ Department of Microbiology, Rivers State University, P.M.B. 5080, Nkpolu-Oroworukwo, Port Harcourt, Rivers \\ State, Nigeria \\ Email: tonye4good62@yahoo.com
}

\section{K. O. Moro}

Department of Microbiology, Rivers State University, P.M.B. 5080, Nkpolu-Oroworukwo, Port Harcourt, Rivers State, Nigeria

\section{P. Peekate}

Department of Microbiology, Rivers State University, P.M.B. 5080, Nkpolu-Oroworukwo, Port Harcourt, Rivers State, Nigeria

\author{
Article History \\ Received: 7 November, 2021 \\ Revised: 26 December, 2021 \\ Accepted: 12 January, 2022 \\ Published: 20 January, 2022 \\ Copyright (C) 2022 ARPG \& \\ Author \\ This work is licensed under \\ the Creative Commons \\ Attribution International \\ (c) $(1)$ CC BY: Creative \\ Commons Attribution License \\ 4.0
}

\begin{abstract}
Vibrio species are autochthonous in the aquatic environment, and are among the leading causes of waterborne disease outbreaks. The ecological prevalence of Vibrio spp. is however influenced by the environmental dynamics of the reservoir system. The study was therefore aimed at assessing the physicochemical as well as seasonal factors that influence the prevalence of Vibrio spp. in some communities in Andoni Local Government Area of Rivers State. A total of 28 water samples collected in two seasons, were subjected to bacteriological and physicochemical analysis, using standard procedures. The data obtained from the study showed that the physicochemical parameters were within WHO permissible limits except for $\mathrm{pH}$ which had mean values within the acidic range and varied between $5.51 \pm 0.32$ during the wet season, and $5.78 \pm 0.79$ during the dry season. Statistical analysis of the data obtained however showed that there was a significant difference $(\mathrm{p}<0.05)$ in the conductivity values with respect to location, sample type (boreholes and wells) and season, TDS, Salinity and $\mathrm{pH}$ were however, significantly different ( $\mathrm{p}<0.05)$ with respect to location only. The study on the prevalence of the Vibrio spp. in the water sources showed a prevalence rate of $29.16 \%$ in the well water samples compared to the borehole water samples with $25 \%$ mean prevalence rate. The prevalence based on location further showed that Inyorong Community had the highest prevalence rate of $50 \%$, followed by Ngo Community with $37.5 \%$ prevalence rate, while Ukwa Community had the lowest prevalence rate of $12.5 \%$. Also, assessment of the seasonal prevalence of the bacteria revealed the occurrence of the isolates was $37.5 \%$ and $16.6 \%$ in the wet and dry season, respectively. The presence of Vibrio spp. in these communities in Andoni Local Government Area is of a public health concern. Regular surveillance alongside preventive measures is therefore recommended for the prevention of cholera related disease outbreaks.
\end{abstract}

Keywords: Andoni; Aquatic reservoirs; Conceptual profile; Vibrio species and physicochemical dynamics.

\section{Introduction}

The family Vibrionaceae consist of seven bacterial genera that are Gram negative, non-spore forming usually curved rods that are either motile or non- motile. They are oxidase positive except $V$. metschnikovii. Vibrio spp. are Classified as halophilic and non-halophilic based on their requirement for sodium chloride [1]. Vibrio infections are still a public health threat as they are usually linked to consumption of seafood and contaminated water. Treatment of vibrio spp. infections depends on the causative strain, treatment ranges from rehydration therapy to debridement of infected tissues from wound infections caused by $V$. vulnificus and administration of antibiotics for severe cholera and systemic infections [2].

Cholera is a disease caused by Vibrio cholerae O1 (classical or ELTor) and O139 [3]. It is a food and waterborne disease that can be transmitted amongst humans and transmission is enhanced by poor sanitary conditions and hygiene, as well as inadequate water supply. The disease also called a disease of poverty is contracted by drinking contaminated water or eating food that has been in contact with contaminated water. This is common in communities lacking proper sewage and water treatment systems [4]. The cholera disease is characterized by diarrheoa (Cholera gravis), vomiting, rapid dehydration, loss of electrolytes (rice water), and muscular cramps. In severe cases suppression of urine, and hypovolemic shock may occur. Renal failure, and cardiac complications can also occur. Without prompt medical attention death occurs in 30 to $40 \%$ of cases, within 48-72 hours [3, 5]. Vibrio parahaemolyticus a gram negative bacteria, that occurs in estuarine, coastal marine water. V. parahaemolyticus is halophilic and autochthonous to marine environment and can cause food/waterborne gastroenteritis in humans especially after consuming water, vegetables, raw or undercooked seafood that is contaminated [6]. It has been implicated in food borne, ear and wound infections and septicemia. Studies of acute diarrhoeal illness in Kolkata, 
India shows that the incidence of gastroenteritis caused by Vibrio parahaemolyticus ranks next to Vibrio cholerae [7] Clinical manifestations associated with $V$. parahaemolyticus infections are gastroenteritis, wound infections, and septicemia. Gastroenteritis is the most common symptom, and manifest as watery diarrhoea which is occasionally bloody. Other symptoms include abdominal pain, headaches, nausea, spewing, and fever. Presence of mucus or blood in feces of patients, results in a gradual decrease in blood pressure. In severe cases internal organs like liver, spleen, lung could be damaged, patients become unconsciousness, pale, go into shock with recurrent convulsions, and death may occur [8].

A times international travelers contribute to the spread of this infection as they move from country to country $[9,10]$. The incidence of vibriosis is on the increase, and this may be greatly enhanced by changes in climate and increase in sea water temperature as vibrio spp. infections have a pattern with highest occurrence in warmer months [2]. Vibrio parahaemolyticus is associated with water temperature and season as studies show that climate change can lead to increase in the numbers of vibrio's and vibrio related illness [9, 10].

Andoni is one of the 23 Local Government Areas in Rivers State, Nigeria, with headquarters at Ngo Town. It occupies an area of over $233 \mathrm{~km}$ with a population of about 311,500 , with economic activities prevalent in this region being mainly fishing [11]. In December 2014 an outbreak of cholera was declared in Andoni Local Government Area of Rivers State. This outbreak ended in February as a result of interventions put in place to stop the spread and transmission of the disease. Investigations revealed that $V$. cholerae non-O1 /non-O139 were causative agents of the outbreak both in stool and water samples [12]. Research has shown that aquatic natural reservoirs (wells) are a potential source and route of cholera transmission, this proves that the water sources were a possible reservoir for $\mathrm{V}$. cholerae non-O1 /non-O139 [5, 13]. Shortfalls in distribution of portable water leads the populace to resort to alternative sources of water which may be unfit for human consumption. The major source of drinking water in Andoni Local Government Area is well water and are usually uncovered wells. These wells can be contaminated by fecal material in hands and by materials used for water collection.

Factors that trigger cholera epidemics in different geographical locations about the same time are unknown but studies suggest a relationship between the biological and physicochemical factors in aquatic reservoirs [13, 14]. Physicochemical factors like temperature, $\mathrm{pH}$, and salinity, influenced by climatic factors facilitates the transmission of cholera disease to humans [15-17]. Hydro-climatic and anthropogenic factors like poor sanitation, human migration, hygiene, international trade and cross border movements also facilitates the spread and transmission of the disease cholera [18]. In recent times the importance of climatic factors in cholera epidemics has been established $[14,19]$.

Due to the inadequacy of treated pipe borne water in most developing countries like Nigeria, people in semi urban and rural areas get drinking water from dug out wells and water vendors [20]. Studies have reported that proximity to sanitary facility influences underground water quality, as the total viable bacterial count and level of contamination decreased with increase in the distance between wells and sanitary facilities [5]. Also wells without covers have been reported to be more contaminated than covered wells [13]. Water in Andoni Local Government Area is usually brackish water and this water may support the growth of V.cholerae and V. parahaemolyticus [6]. Therefore, it is important to analyze parameters like total dissolved solids (TDS), salinity, electrical conductivity, $\mathrm{pH}$ and temperature that may affect the prevalence of the pathogen.

The aim of the study was to therefore evaluate the occurrence of Vibrio species in relation to the prevailing physical, chemical as well as environmental dynamics as associated with the aquatic reservoirs in the study area.

\section{Materials and Method}

\subsection{Study Area}

The sampling sites were located within longitude $7,4129^{\circ} \mathrm{N}$ and latitude $4,4840^{\circ} \mathrm{E}$, Longitude $7,3915^{\circ} \mathrm{N}$ and latitude 4, $4819^{\circ} \mathrm{E}, 10 \mathrm{~m}$ elevation; Longitude $7,4132^{\circ} \mathrm{N}$ and latitude $4,4833^{\circ} \mathrm{E}, 10 \mathrm{~m}$ elevation, and longitude 7,4545 ${ }^{\circ} \mathrm{N}$ and latitude $4,45648^{\circ} \mathrm{E}$.

\subsection{Sample Collection}

Ten stations were selected from three communities affected by a previous cholera outbreak in Andoni Local Government Area, Nigeria. Samples were collected based on standard sampling guidelines from 2 water sources: well and borehole. The samples were collected using sterile containers, placed in a thermos box containing ice packs and transported to the laboratory for analysis.

\subsection{Determination of Physicochemical Factors}

Temperature and $\mathrm{pH}$ of water samples were measured with a portable water thermometer, and a portable $\mathrm{pH}$ meter respectively. Water conductivity, total dissolved solids, salinity were measured using Extech EC500 meter after calibrating the instrument with 1413 standard solution.

\subsection{Identification of Bacterial Isolates}

Identification of bacterial isolates was done on the basis of their cultural and biochemical characteristics. Alkaline peptone water modified with $\mathrm{NaOH}$ (Sodium hydroxide) with final $\mathrm{pH}$ adjusted to 8.4- 8.6 was used to enrich the medium for the isolation of Vibrio spp. Inoculated broths were incubated at 37 degrees centigrade for 8 hours. After incubation, each enriched culture broth was plated directly on Thio-sulfate- Citrate -Bile- Sucrose (TCBS) agar. Agar plates were incubated at 37 degrees centigrade for 24 hours. Yellowish and greenish colonies 2 - 
$3 \mathrm{~mm}$ on agar plate was observed as Vibrio species. Isolated colonies were streaked on blood agar and nutrient agar supplemented with 8.5 percent Sodium Chloride $(\mathrm{NaCl})$ to obtain pure cultures. Isolates were subcultured periodically on nutrient agar slants to maintain pure cultures. Pure culture of isolates was subjected to 10 biochemical testing for presumptive and confirmatory identification of Vibrio spp. The microscopy and biochemical analysis were: Gram staining, oxidase, string, methyl-red, Vogues-Proskauer, indole, citrate utilisation, salt tolerance, blood hemolysis and sugar fermentation tests.

\subsection{Statistical Analysis}

Statistical analysis was carried out on data obtained during the study. One way Anova (Analysis of Variance) statistical tool was used to test for significance. $\mathrm{P}$ values $<0.05$ were considered significantly different and $\mathrm{p} \geq 0.05$ Non-significance respectively.

\section{Results}

\subsection{Physicochemical Properties of Water Samples}

Data obtained from the physicochemistry of the water samples showed the mean temperature values varied from $29.01 \pm 0.78$ (for well water samples) to $29.98 \pm 0.86^{\circ} \mathrm{C}$ (for borehole water samples). The result also showed that the mean total dissolved solids, salinity and conductivity values were observed to be higher for wells compared to boreholes as shown in Table 1 .

The variations in the water quality with respect to electrical conductivity (ED), Total Dissolved Solid (TDS), $\mathrm{pH}$ values were however similar for Ngo and Ukwa communities except for Inyorong community that had lower values of $63.75 \pm 38.21 \mu \mathrm{S} / \mathrm{cm}, 37.08 \pm 21.53 \mathrm{mg} / \mathrm{l}, 0.03 \pm 0.02 \mathrm{ppt}$, and $5.1 \pm 0.35$, for EC, TDS, salinity and pH, respectively. The data showed that Ngo community had the highest $\mathrm{pH}$, TDS, temperature and conductivity values except for salinity values. Inyorong Community had the lowest $\mathrm{pH}$, TDS, temperature, conductivity and salinity values while Ukwa Community had $\mathrm{pH}$, TDS, temperature, conductivity and salinity values similar to values recorded in Ngo community as shown in Table 2 .

The seasonal physicochemical dynamics showed that the mean temperature in the dry season was found to be higher than wet season. For TDS, pH, conductivity and salinity, the values were observed to be higher in dry season than the wet season as shown in Table 3. Overall $\mathrm{pH}$ in wet season was found more acidic than dry season. Also, the overall temperature, TDS, salinity and conductivity values were higher in dry season than wet season.

\subsection{Blood Hemolysis Pattern of the Isolates}

Hemolysis pattern of isolates was analyzed. All isolates exhibited Alpha hemolysis except for one isolate (Nw1A) that exhibited Beta hemolysis as shown in Table 4.

\subsection{Prevalence of Isolates}

The results shown in Figure 1 reveals the prevalence pattern for the Vibrio species isolated from water sources in Andoni Local Government Area. Well samples had higher prevalence of $29.16 \%$ compared to boreholes with $25 \%$ prevalence. The ecological prevalence of the bacteria shows that Inyorong community had the highest occurrence of $50 \%$, followed by Ngo community which had a prevalence of $37.5 \%$, while Ukwa community had lowest prevalence of $12.5 \%$ as seen in Fig. 2. The study on the seasonal presence of the bacteria showed a prevalence of $16.6 \%$ and $37.5 \%$ for the wet season and dry season respectively (Fig.3).

\subsection{Statistical Analysis}

With respect to locations (Inyorong, Ngo, and Ukwa communities), there was a significant difference in conductivity, TDS, salinity and $\mathrm{pH}$ values but there was no difference $(\mathrm{p}>0.05)$ in temperature values $($ Table 2$)$. Statistical analysis based on sample type (boreholes and wells) shows there was a significant difference $(p<0.05)$ in conductivity values but there was no difference $(\mathrm{p}>0.05)$ in TDS, salinity, temperature and $\mathrm{pH}$ values (Table 1$)$. Analysis of water samples in the two seasons showed there was significant difference $(\mathrm{p}<0.05)$ in conductivity values but there was no difference $(\mathrm{p}>0.05)$ in TDS, salinity, temperature and $\mathrm{pH}$ values (Table 3 ).

Table-1. Physicochemical properties of water samples (borehole and well)

\begin{tabular}{l|l|l|l|l|l}
\hline Source & Temperature $\left({ }^{\mathbf{O}} \mathbf{C}\right)$ & Conductivity $(\boldsymbol{\mu S} / \mathbf{c m})$ & TDS $(\mathbf{m g} / \mathbf{l})$ & Salinity $(\mathbf{p p t})$ & $\mathbf{p H}$ \\
\hline Borehole & $29.98 \pm 0.86$ & $40.17 \pm 13.75$ & $29.83 \pm 9.22$ & $0.02 \pm 0$ & $5.64 \pm 0.53$ \\
\hline Well & $29.01 \pm 0.78$ & $184.43 \pm 105.1$ & $92.79 \pm 53.59$ & $0.09 \pm 0.05$ & $5.65 \pm 0.54$ \\
\hline P-value & 0.0728 & 0.0352 & 0.0665 & 0.0801 & 0.9892 \\
\hline Inference & Not significant & Significant & Not significant & Not significant & Not significant \\
\hline
\end{tabular}

Table-2. Physicochemical properties of water samples (study locations)

\begin{tabular}{l|l|l|l|l|l}
\hline Source & Temperture $\left({ }^{\mathbf{O}} \mathbf{C}\right)$ & Conductivity $(\boldsymbol{\mu S} / \mathbf{c m})$ & TDS $(\mathbf{m g} / \mathbf{l})$ & Salinity $(\mathbf{p p t})$ & $\mathbf{p H}$ \\
\hline INYORONG & $28.98 \pm 1.04^{\mathrm{a}}$ & $63.75 \pm 38.21^{\mathrm{a}}$ & $37.08 \pm 21.53^{\mathrm{a}}$ & $0.03 \pm 0.02^{\mathrm{a}}$ & $5.1 \pm 0.35^{\mathrm{a}}$ \\
\hline NGO & $29.23 \pm 1.02^{\mathrm{a}}$ & $219 \pm 137.44^{\mathrm{b}}$ & $119.33 \pm 67.1^{\mathrm{b}}$ & $0.1 \pm 0.06^{\mathrm{b}}$ & $6.07 \pm 0.3^{\mathrm{b}}$ \\
\hline UKWA & $29.38 \pm 0.44^{\mathrm{a}}$ & $201.2 \pm 46.7^{\mathrm{ab}}$ & $90 \pm 20.39^{\mathrm{ab}}$ & $0.11 \pm 0.03^{\mathrm{b}}$ & $5.79 \pm 0.3^{\mathrm{b}}$ \\
\hline P-value & 0.7541 & 0.0185 & 0.0174 & 0.0148 & 0.0004 \\
\hline Inference & Not significant & Significant & Significant & Significant & Significant \\
\hline
\end{tabular}


Academic Journal of Life Sciences

Table-3. Physicochemical properties of water samples (dry and wet season)

\begin{tabular}{l|l|l|l|l|l}
\hline Source & Temperature $\left({ }^{\mathbf{0}} \mathbf{C}\right)$ & Conductivity $(\boldsymbol{\mu S} / \mathbf{c m})$ & TDS $(\mathbf{m g} / \mathbf{L})$ & Salinity $(\mathbf{p p t})$ & $\mathbf{p H}$ \\
\hline Dry & $29.64 \pm 1.17$ & $161.53 \pm 111.78$ & $98.65 \pm 67.47$ & $0.08 \pm 0.06$ & $5.78 \pm 0.79$ \\
\hline Wet & $28.73 \pm 0.8$ & $156.41 \pm 109.3$ & $64.71 \pm 46.37$ & $0.07 \pm 0.05$ & $5.51 \pm 0.32$ \\
\hline P-value & 0.0128 & 0.8935 & 0.097 & 0.5026 & 0.2048 \\
\hline Inference & Not significant & Significant & Not significant & Not significant & Not significant \\
\hline
\end{tabular}

Table-4. Blood hemolysis pattern of isolates (dry and wet season).

\begin{tabular}{l|l|l}
\hline S/N & Isolate Code & Hemolysis Pattern \\
\hline $\mathbf{1 .}$ & NW1(A) & Beta \\
\hline $\mathbf{2 .}$ & NW3(B) & Alpha \\
\hline $\mathbf{3 .}$ & UW2(A) & Alpha \\
\hline $\mathbf{4 .}$ & NW2(B) & Alpha \\
\hline $\mathbf{5 .}$ & NW3(B) & Alpha \\
\hline $\mathbf{6 .}$ & IW1(B) & Alpha \\
\hline $\mathbf{7 .}$ & IW2(A) & Alpha \\
\hline $\mathbf{8 .}$ & IB1(A) & Alpha \\
\hline
\end{tabular}

Fig-1. Occurrence of vibrio isolates in water sources

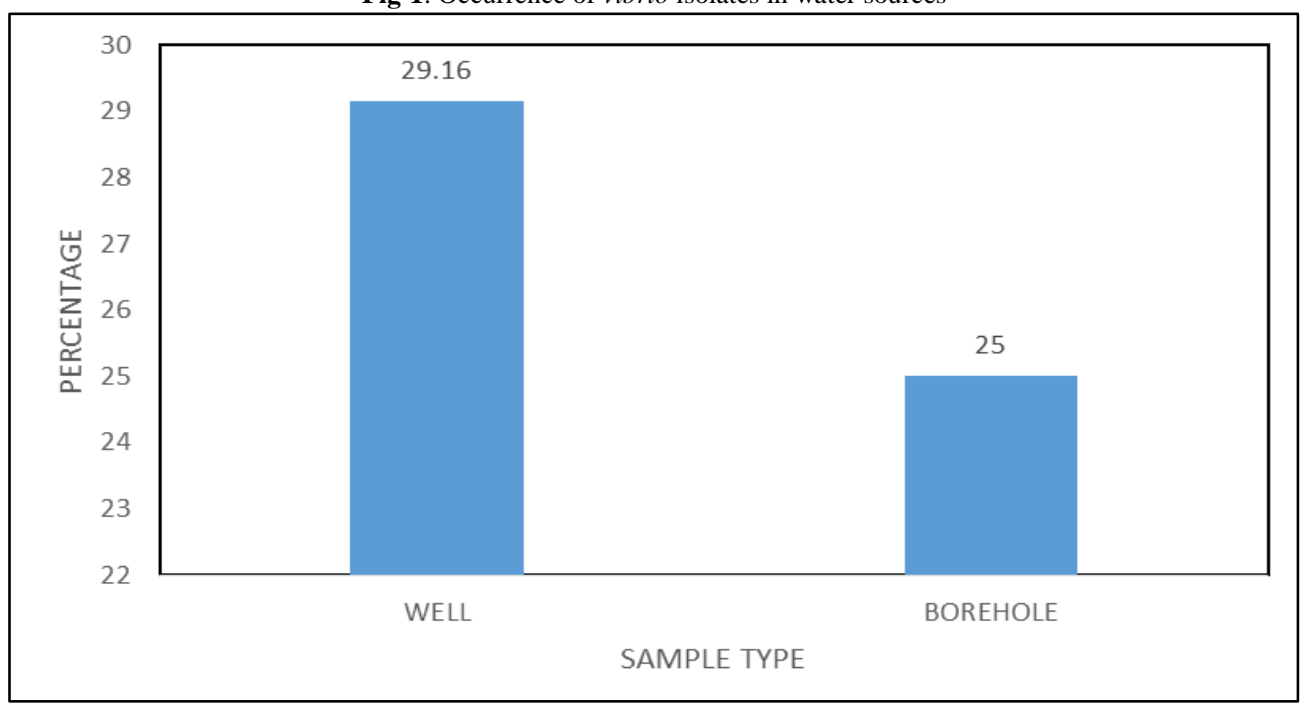

Fig-2. Occurrence of vibrio isolates in water sources from different locations (Communities)

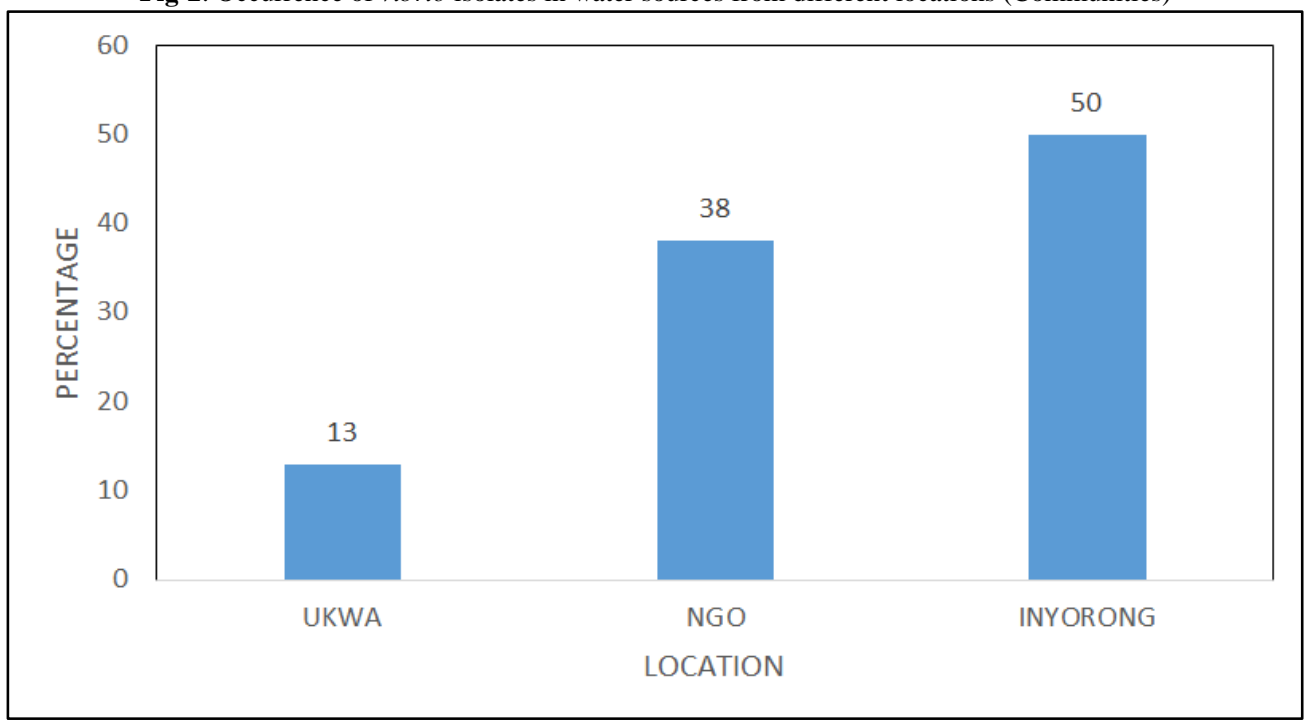


Fig-3. Seasonal occurrence of vibrio isolates in water sources

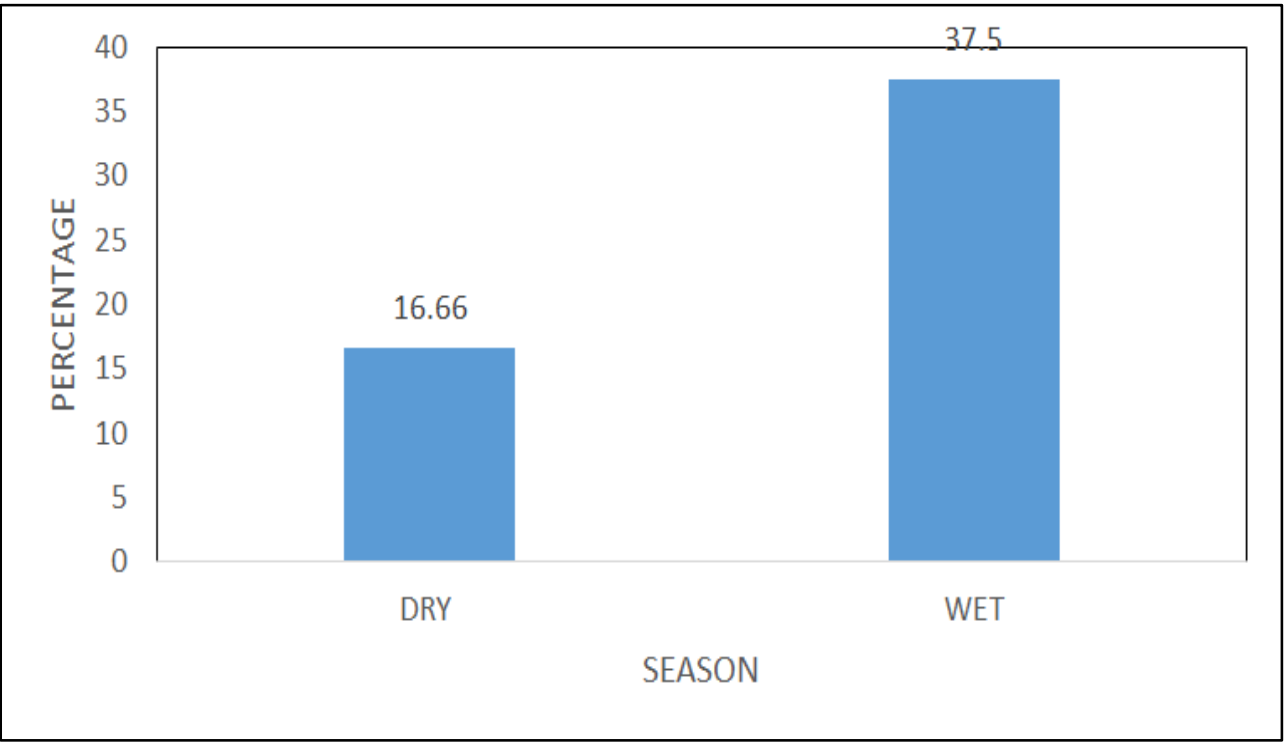

\section{Discussion}

\subsection{Physicochemical Properties of Water Samples}

In order to improve disease forecasting at longer time scales, understanding the influence of physicochemical factors and seasonal patterns of Vibrio spp. is important [4]. Data from physicochemical analysis showed there were no difference between mean $\mathrm{pH}$ of borehole and well samples. This observation is in line with the data obtained by Wemedo, et al. [21] on the nitrate to phosphate ratio and other physicochemical characteristics of different water sources in Yeghe Community, Rivers State, Nigeria. The researchers observed no significant difference between the $\mathrm{pH}$ of the borehole and well water sources. However, different factors are known to influence the $\mathrm{pH}$ of water, including manmade and natural conditions [21].

On the other hand, the mean temperature values of borehole water were slightly higher than well water, and this could be because of the metallic nature of storage tanks as metals have been known to be good conductors of heat. Mean total dissolved solids values were higher for wells compared to borehole samples. This may account for the increase in mean conductivity values of well samples as larger amounts of dissolved salts and organic matter increases conductivity. An excessive increase in the concentration of dissolved ionic solids within water samples (TDS) is the result of an increase in conductivity as conductivity and TDS show ionic load and contaminants present in water [22]. This may account for correlation between high conductivity values of well samples and high salinity values (Table 1). Chlorination of borehole water may also account for a lower salinity, TDS, and conductivity values.

The studies on the physicochemical properties of the water samples based on locations (communities) showed there were significant differences $(\mathrm{p}<0.05)$ in the mean conductivity values. This is proof that water samples were from different sources and seasonal variations can increase or decrease water conductivity. Mean conductivity, TDS, $\mathrm{pH}$ values of $\mathrm{Ngo}$ and Ukwa community were similar compared to the Inyorong community, and this may be due to proximity/closeness of both communities compared to the Inyorong community that is farther. A research on the community water sources in Primary Schools of Pakistan reported a variation in TDS with respect to location studied [23]. This is consistent with findings in this study (Table 2). Mean salinity values in Ukwa community was higher than Ngo community, and this may be due to the topography /terrain of the land.

Also the seasonal influence was determined in this study. The mean temperature in dry season was found to be higher than wet season as dry seasons have been known to be hotter with consistent increase in temperature compared to wet season with less sunshine, and regular rainfall. A research by Ahmed, et al. [23] on drinking water in India reported that excessive evaporation of water from a large river and lake as a result of increase temperature increased the conductivity, as this is consistent with findings in this study in dry season. Studies also show positive correlation between rainfall, temperature and Vibrio parahaemolyticus prevalence Sobrinho, et al. [24]. This is consistent with findings in this study as increased temperature alongside heavy rainfall may have been responsible for higher prevalence of Vibrio parahaemolyticus in wet season (Table 3). During wet season water becomes less saline due to an increase in water volume compared to the warmer dry season where water decreases in volume as temperature increases because of excessive evaporation [25]. This finding by Eseigbe and his colleagues is consistent with this study as a lower salinity, TDS and conductivity value was reported in wet than dry season (Table 3). According to Eseigbe, et al. [25] water with low $\mathrm{pH}$ values is acidic, soft, and corrosive due to presence of organic matter and acidic substances, such as microorganisms which generate excessive levels of $2 S O$ ( $g$ ). A research by Kalwale and Savale [26] observed that $\mathrm{pH}$ of water was high in summer and rainy seasons depending on photosynthetic activity but this research work showed that $\mathrm{pH}$ was higher in dry season than wet season (Table 3). Increase in acidity of water in wet season (Table 3) may be as a result of acid rains as most wells in this area are open/uncovered. Studies by Kalwale and Savale [26] also reported that $\mathrm{pH}$ of water was high in summer season. This is consistent with findings in this study where a higher $\mathrm{pH}$ was reported for the dry than wet season 
Statistical analysis of water sources showed there was significant difference $(\mathrm{p}<0.05)$ in conductivity values with respect to location, sample type (boreholes and wells) and season (dry and wet), this is a proof that water samples were from different sources and seasonal variations can increase or decrease water conductivity.

\subsection{Prevalence of the Isolates}

The Prevalence of the isolates were analyzed based on sample type (well and borehole), location (communities) and season. Well water samples had a higher prevalence of $29.16 \%$ compared to the boreholes with $25 \%$ prevalence rate. This could be due to the fact that most wells were opened and uncovered and contamination of these wells could occur during water collection processes due to the presence of fecal material in hands and by materials used to collect water. The Inyorong Community had the highest prevalence rate of 50\%, Ngo Community had a prevalence of $37.5 \%$ while Ukwa Community had the lowest prevalence of $12.5 \%$. Higher prevalence rate in Inyorong Community may be due to seasonal variation as studies by Ingelbeen and his colleagues in Democratic Republic of Congo reported 53,000 cases and 1,145 deaths from cholera infections as a result of a spread of the pathogen to nonendemic areas that where cholera free possible due to less appropriate prevention and treatment strategies [27]. Wet season had a prevalence of $37.5 \%$ while dry season had a prevalence of $16.6 \%$. Inundation or breakdown of sanitary infrastructure, occurring as a result of heavy rainfall and flooding of water supply intended for human consumption may be responsible for a higher prevalence in wet season [28].

\section{Conclusion}

The study reported the importance of physicochemical factors (temperature, total dissolved solids (TDS), $\mathrm{pH}$, salinity, conductivity), and how it influences prevalence of Vibrio spp. in some communities in Andoni Local Government Area. Statistical analysis of locations studied show that conductivity, TDS, salinity, pH was significantly different $(\mathrm{p}<0.05)$. Conductivity values of sample type, seasons, and locations studied were also significantly different $(\mathrm{p}<0.05)$. Prevalence of Vibrio spp was reported higher in well samples, wet season and in Inyorong community. This showed the influence of seasonal variation and geographical location on prevalence of Vibrio spp. Presence of Vibrio spp. in water samples makes it unsafe for drinking due to microbiological contamination.

Boreholes should be regularly assessed for their microbial and physicochemical quality, treated, before supply, to ensure public health safety when water is consumed in these communities. A clear understanding of the mechanisms that link seasonal changes to disease outbreaks is necessary for developing control strategies. Endemic strains may increase in the future due to climate change, anthropogenic activities, and transport due to travel and trade, this will create focal points for disease outbreaks. Therefore, geographic information systems (GIS) should be used to determine hotspots, as this will enable implementation of health development programs and administration of vaccine where applicable. Provision and access to clean and safe water supply cannot be over emphasized. Provision of modern sanitary facilities will reduce transmission pathways. Regular monitoring and education for water collection, treatment and storage practices must be ensured.

Further investigations beyond this study is important to understand the influence of physicochemical factors on behavior, growth, and multiplication of Vibrio spp. in Andoni. It is important to obtain data regularly on Vibrio spp. for biosafety/micro risk assessment. Regular surveillance, improved policy development and preparedness alongside implementation of WASH interventions should be a standard approach for developing a conceptual framework to decipher factors that might influence prevalence of Vibrio spp. in Andoni Local Government Area, this will help prevent reoccurrence of an outbreak in the future.

\section{References}

[1] Osunla, C. A. and Okoh, A. I., 2017. "Vibrio pathogens: A public health concern in rural water resources in Sub Saharan Africa." International Journal of Environmental Res Public Health, vol. 14, p. 1188.

[2] Baker-Austin, C., Oliver, J. D., Alam, M., and Martinez-Urtaza., J., 2018. "Vibrio spp. infections." Nat. Res. Dis., vol. 4, pp. 1-19.

[3] Adagbada, A. O., Adesida, S. A., Nwakorie, F. O., Neimogba, M. T., and A.O., C., 2012. "Cholera epidemiology in Nigeria: An overview." Pan African Medical Journal, vol. 12, p. 1627.

[4] Sedas, V. T., 2007. "Influence of environmental factors on the presence of Vibrio cholerae in the marine environment: a climate link." The Journal of Infection in Developing Countries, vol. 1, pp. 224-241.

[5] Akoachere, K. T., Omam, L., and Massalla, T. N., 2013. "Assessment of the relationship between bacteriological quality of dug wells, hygiene behavior and well characteristics in two cholera endemic communities in Duouala. Cameroon." BMC. Public Health, vol. 13, p. 692.

[6] Prabhakaran, M., Ramamurthy, T., and Sabu, T., 2020. "Genetic and virulence characterization of Vibrio parahaemolyticus isolated from Indian coast Divya." BMC Microbiolog, vol. 20, pp. 1-14.

[7] Rodgers, C., Parveen, S., Chigbu, P., Jacob, J., Rhodes, M., and Harter- Dennis, J., 2014. "Prevalence of vibrio parahemolyticus, and, vibrio vulnificus in blue crabs (callinectes sapidus) seawater and sediments of the maryland coastal bays." Journal of Applied Microbiology, vol. 117, pp. 1198-1209.

[8] Wang, R., Zhong, Y., Gu, X., Yuan, J., Saeed, A. F., and Wang, S., 2015. "The pathogenesis, detection and prevention of vibrio parahaemolysis." Frontiers in Microbiology, vol. 6, pp. 1-13. 
[9] Pal, N. D., 2010. "Isolation, identification and molecular characterization of Vibrio parahaemolyticus from fish samples in Kolkata." European Review for Medical and Pharmacological Sciences, vol. 14, pp. 545549.

[10] Sen, U. and Garode, A. M., 2018. "Prevalence of Vibrio cholerae and its probiotic interactions in frozen buffalo meat at abattoir." Journal of Bacteriology and Mycology, vol. 6, p. 00178.

[11] Tasie, C. M. and Wilcox, G. I., 2018. "An appraisal of artisanal fishery enterprises in andoni loal government area of Rivers State, Nigeria." Greener Journal of Agricultural Sciences, vol. 8, pp. 257-265.

[12] Rivers State Ministry of Health, 2015. Cholera outbreak investigation in Andoni. Local Government Area of Rivers State.

[13] Filho, M. J., Lopez, R. M., Rivera, I. N., and Colwell, R. R., 2016. "Are natural reservoirs important for cholera surveillance? The case of an outbreak in Brazilian estuary." Journal of Applied Microbiology, vol. 63, pp. 183-188.

[14] Huq, A. R., Sack, B., Nizam, A., Longini, I. M., Nair, G. B., Ali, A., Morris, J. G., Khan, M. N., Siddique, K., et al., 2005. "Critical factors influencing the occurrence of vibrio cholerae in the environment of bangladesh. Center of marine biotechnology, University of Maryland Biotechnology Institute, Baltimore, Maryland." Journal of Applied and Environmental Microbiology, vol. 71, pp. 4645-4654.

[15] Emch, M., Feldacker, C., S., I. M., and Ali, M., 2008. "Seasonality of cholera from 1974 to 2005: A review of global patterns. International journal of health geographic's." vol. 7, p. 31.

[16] Hashizume, M., Armstong, B., Hajat, S., Tachii, H., and Sack, D., 2008. "The effect of rainfall on the incidence of cholera in Bangladesh." Epidemiology, vol. 19, pp. 103-110.

[17] Fernandez, M., Bauernfeind, A., Jimenez, J. D., Gil, C. L., Omeiri, N. E., and Guibert, H. R., 2009. "Influence of temperature and rainfall on the evolution of cholera epidemics in Lusaka, Zambia, 2003-2006: Analysis of a time series." Transactions of the Royal Society of Tropical Medicine and Hygiene, vol. 3, pp. 137-143.

[18] Bwire, G., Debes, A. K., G., O. C., Kagirita, Atek, Ram, M., Komakech, H., J., V. B., Buyinza, A. W., et al., 2018. "Environmental surveillance of Vibrio cholerae O1/O139 in the five African Great lakes and to the major surface water sources in Uganda." Frontiers in Microbiology, p. 1560. Available: https://pubmed.ncbi.nlm.nih.gov/30123189/

[19] Gwezi, W. and Sangayado, E., 2019. "Recurrent cholera outbreaks in Sub Saharan Africa moving beyond epidemiology to understand the environmental reservoirs and drivers." MDPI Journal, vol. 10, p. 1.

[20] Aboh, E. A., Giwa, F. J., and Giwa, A., 2015. "Microbiological assessment of well waters in Samaru, Zaria, Kaduna, State, Nigeria." Annals of African Medicine, vol. 14, pp. 32-8.

[21] Wemedo, S. A., Sampson, T., and Dick, B., 2021. "Evaluating the nitrate to phosphate ratio and other physicochemical characteristics of different water sources in Yeghe community, rivers state, Nigeria." Asian Journal of Environment and Ecology, vol. 15, pp. 1-9.

[22] Oyem, H. H., Oyem, I. M., and Ezeweali, D., 2014. "Temperature, pH, electrical conductivity, total dissolved solids and chemical oxygen demand of ground water in Boji-BojiAgbor/Owa Area and immediate Suburbs." Research Journal of Environmental Sciences, vol. 8, pp. 444-450.

[23] Ahmed, J., Wong, L. P., Chua, Y. P., and Channa, N., 2020. "Drinking water quality mapping using water quality index and geospatial analysis in primary schools of Pakistan." vol. 12, pp. 1-18.

[24] Sobrinho, S. C., Destro, M. T., Franco, B. G., and Landgra, F. M., 2010. "Correlation between Environmental Factors and Prevalence of Vibrio parahaemolyticus in oysters harvested in the Southern Coastal Area of Sao Paulo State, Brazil." Applied and Environmental Microbiology, vol. 76, pp. 1290-1293.

[25] Eseigbe, A. P., Ibhadode, O., Ayoola, A. R., and Sosanolu, O. M., 2018. "Experimental determination of drinking water quality in Abeokuta Metropolis, South-Western Nigeria." International Journal of Advances in Scientific Research and Engineering, vol. 4, pp. 241-256.

[26] Kalwale, A. M. and Savale, P. A., 2012. "Determination of physico-chemical parameters of deoli bhorus dam water." Advances in Applied Science Research, vol. 3, pp. 273-279.

[27] Ingelbeen, B., Hendricks, D., Miwanda, B., Van der Sande, M., Mossoko, M., Vochten, H., Riems, B., Nyakio, J., Vanlerberghe, V., et al., 2019. "Recurrent cholera outbreaks, democratic republic of the Congo, 2008-2010." Journal of Emerging Infectious Diseases, vol. 25, pp. 856-864.

[28] Maheshwari, M., Nelapat, K., and Kiranmayii, B., 2011. "Vibrio cholerae-A review." Journal of Vertinary World, vol. 4, pp. 423-428. 